\title{
Aldosterone impairs vascular reactivity by decreasing glucose-6-phosphate dehydrogenase activity
}

\author{
Jane A. Leopold, M.D. ${ }^{1,2}$, Aamir Dam, B.S. ${ }^{1}$, Bradley A. Maron, M.D. ${ }^{1,2}$, Anne W. Scribner, \\ B.S. ${ }^{1}$, Ronglih Liao, Ph.D. ${ }^{1,2}$, Diane E. Handy, Ph.D. ${ }^{1,2}$, Robert C. Stanton, M.D. ${ }^{3}$, Bertram \\ Pitt, M.D. ${ }^{4}$, and Joseph Loscalzo, M.D., Ph. D. ${ }^{1,2}$ \\ ${ }^{1}$ Whitaker Cardiovascular Institute, 700 Albany Street, Boston University School of Medicine, \\ Boston, MA 02118 \\ ${ }^{3}$ Renal Section, Joslin Diabetes Center, 1 Joslin Place, Harvard Medical School, Boston, MA \\ 02215
}

${ }^{4}$ Division of Cardiology, University of Michigan School of Medicine, Taubman Medical Center, 1500 E. Medical Center Drive, Ann Arbor, MI 48109

\begin{abstract}
Hyperaldosteronism is associated with impaired vascular reactivity; however, the mechanism by which aldosterone promotes endothelial dysfunction remains unknown. Glucose-6-phosphate dehydrogenase (G6pd), the principal source of Nadph, modulates vascular function by limiting oxidant stress to preserve bioavailable nitric oxide $\left(\mathrm{NO}^{\circ}\right)$. In these studies, we show that aldosterone $\left(10^{-9}-10^{-7} \mathrm{~mol} / \mathrm{l}\right)$ decreases endothelial G6pd expression and activity in vitro resulting in increased oxidant stress and decreased cGMP levels similar to what is observed in G6pddeficient cells. Aldosterone decreases G6pd expression by protein kinase A activation to increase expression of Crem, which interferes with Creb binding to the G6pd promoter. In vivo, infusion of aldosterone decreases vascular G6pd expression and impairs vascular reactivity. These effects are abrogated by spironolactone or vascular gene transfer of $G 6 \mathrm{pd}$. These studies demonstrate that aldosterone induces a G6pd-deficient phenotype to impair endothelial function; aldosterone antagonism or gene transfer of G6pd improves vascular reactivity by restoring G6pd activity.
\end{abstract}

\section{Keywords}

aldosterone; G6PD; nitric oxide; oxidant stress; spironolactone; vascular reactivity

Corresponding author: Jane A. Leopold, M.D., Cardiovascular Medicine Division, Department of Medicine, Brigham and Women's Hospital, Harvard Medical School, 77 Avenue Louis Pasteur NRB 0630K, Boston, MA 02115, Phone: (617) 525-4846, Fax: (617) 525-4830, jleopold@ partners.org.

${ }^{2}$ Current affiliation: Cardiovascular Medicine Division, Department of Medicine, Brigham and Women's Hospital, Harvard Medical School, 77 Avenue Louis Pasteur, Boston, MA 02115

This is an un-copyedited author manuscript that was accepted for publication in Nature Medicine, copyright Nature Publishing Group. This may not be duplicated or reproduced, other than for personal use or within the "Fair Use of Copyrighted Materials" (section 107, title 17, U.S. Code) without prior permission of the copyright owner, Nature Publishing Group. The final copyedited article, which is the version of record, can be found at Nature Medicine. The Nature Publishing Group disclaims any responsibility or liability for errors or omissions in this version of the manuscript or in any version derived from it by the National Institutes of Health or other parties.

AUTHOR CONTRIBUTIONS:

J.A.L. designed the study, supervised the project, conducted experiments, and wrote the manuscript; A.D. contributed to the in vitro and in vivo studies; B.A.M., A.W.S., D.E.H., and R.C.S contributed to the in vitro studies; R.L. contributed to the in vivo studies; B.P. contributed to data interpretation; and J.L. contributed to data interpretation and manuscript critique.

COMPETING FINANCIAL INTERESTS:

B.P. reports that he is a consultant for Pfizer, Novartis, Alteon, and Astra Zeneca 
Hyperaldosteronism has been associated with impaired vascular reactivity in individuals with an aldosterone-producing adrenal adenoma, hypertension, or congestive heart failure ${ }^{1,2}$ that is improved significantly following surgical resection of the adenoma ${ }^{3}$ or treatment with spironolactone ${ }^{4}$. The mechanisms by which aldosterone adversely influences vascular reactivity remain to be elucidated; however, it has been suggested that aldosterone initiates these pathological effects by inducing a vasculopathy characterized by increased vascular reactive oxygen species (ROS) and decreased endothelium-derived bioavailable nitric oxide $\left(\mathrm{NO}^{\circ}\right)^{5}$.

Glucose-6-phosphate dehydrogenase (G6pd), the first and rate-limiting enzyme in the pentose phosphate pathway, is the principal intracellular source of Nadph. Nadph is utilized as a reducing equivalent to limit ROS and maintain levels of reduced glutathione (GSH) ${ }^{6}$. Thus, G6pd is a critical determinant of the intracellular redox state and provides a redox environment that favors $\mathrm{NO}^{*}$. When G6pd activity is deficient, endothelial cells challenged with oxidants demonstrate increased ROS and decreased GSH stores ${ }^{6}$ while cells that overexpress G6pd remain resistant to redox imbalance ${ }^{7}$. G6pd-derived Nadph also serves as a cofactor for the endothelial isoform of nitric oxide synthase (eNos). The importance of G6pd for eNos activity is revealed when Nadph stores are depleted: eNos uncouples and generates superoxide in preference to $\mathrm{NO}^{*}$. In contrast, overexpression of G6pd increases eNos activity and augments $\mathrm{NO}^{\bullet}$ formation ${ }^{7}$.

Early studies have shown that select glucocorticoid, mineralocorticoid, and sex steroid compounds inhibit G6pd activity ${ }^{8}$. While the effect of aldosterone on G6pd activity was not evaluated, dehydroepiandrosterone, which is structurally similar to aldosterone, was found to be a potent inhibitor of G6pd ${ }^{8}$. Interestingly, aldosterone was shown to decrease G6pd activity in rat myocardial homogenates when injected twice daily for $17 \mathrm{~d}^{9}$. Taken together, these studies raise the possibility that aldosterone may induce a G6pd-deficient state to promote vascular dysfunction. To date, there have been no studies that have examined the effects of aldosterone on G6pd and the consequences on endothelial function and vascular reactivity.

\section{Results}

To evaluate the effects of aldosterone on G6pd, we exposed bovine aortic endothelial cells (BAEC) to aldosterone $\left(10^{-9}-10^{-7} \mathrm{~mol} / \mathrm{l}\right)$ for $12-48 \mathrm{~h}$ and examined mineralocorticoid receptor (MR) expression, G6pd expression, and activity. Aldosterone did not influence MR expression (Fig. 1a); however, by $24 \mathrm{~h}$, aldosterone-treated cells demonstrated a concentration-dependent decrease in G6pd protein expression (Fig. 1b) and mRNA levels (Fig. 1c, d) resulting in decreased G6pd activity (Fig. 1e) and Nadph levels (Fig. 1f) compared to vehicle-treated cells. As we saw no further decrease in G6pd at the $36 \mathrm{~h}$ time point, we elected to perform experiments following a $24 \mathrm{~h}$ incubation period. To demonstrate that these findings were not unique to BAEC, we performed similar studies in human coronary artery endothelial cells; exposure to aldosterone resulted in a similar decrease in G6PD protein expression, mRNA levels, and activity (Supplementary Fig. 1 online).

\section{Protein kinase A activation decreases G6pd expression}

To determine the mechanism by which aldosterone decreased G6pd expression, we next examined cAMP levels and protein kinase A (PkA) activity as PkA activation has been associated with decreased G6pd activity ${ }^{10,11}$. Exposure to aldosterone increased cAMP levels and PkA activity despite similar PkA protein levels between treatment groups (Supplementary Fig. 2 online). PkA activation, in turn, increased phosphorylation of cyclic 
AMP-response element binding protein (Creb) at Ser133, but not total Creb or Creb binding protein levels (Fig. 2a).

While activation of Creb is associated with upregulation of gene transcription, in aldosterone-treated cells, we observed a downregulation of G6pd mRNA. We, therefore, examined expression of the cyclic AMP-response element modulator (Crem), an endogenous inhibitor of gene transcription driven by $\mathrm{Creb}^{12}$ and found that $\mathrm{Crem}$ protein expression (Fig. 2b) and mRNA levels (Fig. 2c) were increased in aldosterone-treated cells. We next performed a nuclear run-on assay utilizing nuclei isolated from cells exposed to aldosterone that were transfected with $C r e b$ or $C r e m$ siRNA to demonstrate that Crem, and not Creb, modulated inhibition of G6pd gene transcription (Supplementary Fig. 2). In the presence of aldosterone, cells transfected with $C r e b$ siRNA to decrease expression by $72 \%$, showed no difference in $G 6 p d$ gene transcription as compared to vehicle-treated cells. In contrast, when Crem expression was down-regulated by 66\%, G6pd expression was restored to levels similar to that observed in vehicle-treated cells (Supplementary Fig. 3 online and Fig. 2d).

We next determined that increased Crem expression was dependent upon on PkA activation. We treated cells with aldosterone in the presence of the specific cell-permeable PkA inhibitor 14-22 amide (PKI) $(10 \mu \mathrm{mol} / \mathrm{l})$. PKI inhibited PkA activity (Supplementary Fig. 2) resulting in decreased Crem protein and mRNA levels (Fig. 2b, c) and increased G6pd protein expression in aldosterone-treated cells (Supplementary Fig. 2), despite decreased Creb phosphorylation (Fig. 2a). We observed similar effects when we inhibited MR activation by treating cells with spironolactone $(10 \mu \mathrm{mol} / \mathrm{l})$ (Supplementary Fig. 2 and Fig. $2 \mathrm{a}-\mathrm{c})$. To confirm that our observations were mediated by activation of PkA and not other kinases known to activate Creb, we examined expression of Msk, $\mathrm{Ca}^{2+}$-calmodulin kinase, p90Rsk, and p44/42 Mapk, and found no difference in expression between treatment groups. Furthermore, we found no difference in serum-glucocorticoid kinase (Sgk), phospho-Sgk, or Sgk activity between vehicle-treated and aldosterone-treated cells (Supplementary Fig. 4 online).

Next, we determined the mechanism by which aldosterone decreases G6PD expression using human coronary artery endothelial cells. We examined a $1 \mathrm{~kb}$ segment of the G6PD promoter upstream of the transcription start site to identify CREB binding sequences. We identified a single site (-889--881) containing the sequence $5^{\prime}$-TGACGATA- $3^{\prime}$, which has been confirmed ${ }^{13}$ and reported to bind both CREB and CREM ${ }^{14}$. We performed a mobility shift assay to demonstrate that CREB/CREM protein-DNA binding occurred in aldosteronetreated cells at this site (Fig. 2e). In vehicle-treated cells, there was a specific protein-DNA complex (lane 2) that was abolished in the presence of excess unlabeled oligonucleotide (lane 5). A CREB antibody supershifted this complex (lane 3), while incubation with a CREM antibody (lane 4) did not produce this effect. In contrast, in aldosterone-treated cells, there was evidence of supershift by both CREB and CREM antibodies (lanes 7-8). In addition, we assessed other downstream effects of CREB activation by examining DNA binding to NF- $\kappa$ B and ATF-2; there was no difference observed between aldosterone-treated and vehicle-treated cells (Supplementary Fig. 4).

We also performed chromatin immunoprecipitation assays to confirm the association of CREB and CREM to the G6PD promoter. In vehicle-treated cells, only CREB was associated with the $G 6 P D$ promoter; in contrast, in aldosterone-treated cells, both CREB and CREM associated with the G6PD promoter (Fig. 2f). Both inhibition of PKA with PKI or MR inhibition with spironolactone completely blocked the aldosterone-mediated recruitment of CREM to the G6PD promoter. 


\section{Aldosterone modulates oxidant stress and NO• levels}

To determine the consequences of the aldosterone-induced G6pd-deficient phenotype on ROS accumulation, we measured 6-carboxy- $2^{\prime}-7^{\prime}$ dichlorodihydrofluorescein fluorescence as a non-specific marker of oxidant stress. As compared to vehicle-treated cells, cells exposed to aldosterone demonstrated increased ROS levels (Fig. 3a), mostly derived from eNos and Nadph oxidase (Supplementary Fig. 5 online), that was associated with a concomitant decrease in the GSH/GSSG ratio (Fig. 3b).

We next examined eNos activity in aldosterone-treated BAEC in the absence of exogenous cofactors. In this manner, eNos activity is dependent upon ambient Nadph levels. Compared to vehicle-treated cells, eNos activity was decreased significantly in aldosterone-treated cells $\left(10^{-7} \mathrm{~mol} / \mathrm{l}\right)$ (Fig. 3c), that did not result from a decrease in eNos expression (Fig. 3d); however, there was a shift in the eNos monomer-dimer ratio, which has been associated with eNos uncoupling ${ }^{15,16}$ (Fig. 3d). To demonstrate that the observed decrease in eNos activity resulted from depleted Nadph stores owing to deficient G6pd activity, we measured eNos activity in cell homogenates in the presence of exogenous Nadph and found that eNos activity in aldosterone-treated cells was similar to that observed in vehicle-treated cells (872 \pm 46 vs. $923 \pm 62 \mathrm{cpm}, P=\mathrm{NS}, \mathrm{n}=4)$.

Next, we examined cGMP levels as a measure of bioavailable $\mathrm{NO}^{\circ}$. In unstimulated cells, cGMP levels were decreased in aldosterone-treated $\left(10^{-7} \mathrm{~mol} / \mathrm{l}\right) \mathrm{BAEC}$ as compared to control cells $(0.6 \pm 0.1 \mathrm{vs} .1 .3 \pm 0.1 \mathrm{pmol} \mathrm{cGMP} / \mathrm{mg}$ protein, $P<0.01, \mathrm{n}=6)$. When stimulated with bradykinin $(5 \mu \mathrm{mol} / \mathrm{l})$, aldosterone-treated cells demonstrated a concentration-dependent decrease in cGMP production ( $1.4 \pm 0.2$ vs. $0.9 \pm 0.1$ vs. $0.7 \pm 0.1$ $\mathrm{pmol} \mathrm{cGMP} / \mathrm{mg}$ protein, $P<0.01, \mathrm{n}=6)$ compared to control cells $(2.0 \pm 0.1 \mathrm{pmol} \mathrm{cGMP} /$ $\mathrm{mg}$ protein) that paralleled the inhibition of eNos activity (Fig. 3e).

\section{G6pd-deficient endothelial cells and aldosterone}

To confirm that aldosterone increased ROS and decreased eNos activity by inhibiting G6pd, we examined these parameters in G6pd-deficient endothelial cells isolated from aortas of G6PD-deficient male mice ${ }^{17}$. Under basal conditions, G6pd activity (32.6 \pm 6.1 vs. 128.4 \pm 12.8 units $/ 6 \mathrm{~min} / \mathrm{mg}$ protein, $P<0.01, \mathrm{n}=8)$ and Nadph levels $(1.0 \pm 0.04$ vs. $2.1 \pm 0.03$ $\mathrm{mmol} / \mathrm{l} / \mathrm{mg}$ protein, $P<0.01, \mathrm{n}=4$ ) were decreased significantly in G6pd-deficient cells compared to those isolated from $\mathrm{C} 3 \mathrm{H}$ wild-type mice. G6pd-deficient cells were characterized further by increased ROS $(132.3 \pm 4.9$ vs. $44.4 \pm 5.1$ fluorescence units, $P<$ $0.01, \mathrm{n}=8)$, decreased eNos activity $(402.2 \pm 22.9$ vs. $998.9 \pm 33.3 \mathrm{cpm}, P<0.01, \mathrm{n}=3)$, and decreased acetylcholine $(1 \mu \mathrm{mol} / \mathrm{L})-$ stimulated cGMP levels $(0.8 \pm 0.2$ vs. $2.7 \pm 0.1$ $\mathrm{pmol} \mathrm{cGMP/mg} \mathrm{protein,} P<0.01, \mathrm{n}=4)$.

While exposure to aldosterone decreased G6pd activity in wild-type cells, there was no further decrease in activity in G6pd-deficient cells $(41.5 \pm 3.2$ vs. $46.4 \pm 6.5$ units $/ 6 \mathrm{~min} / \mathrm{mg}$ protein, $P=\mathrm{NS}, \mathrm{n}=8)$. Furthermore, aldosterone $\left(10^{-7} \mathrm{~mol} / \mathrm{l}\right)$ did not increase ROS $(126.4$ \pm 9.8 vs. $131.4 \pm 15.0$ fluorescence units, $P=\mathrm{NS}, \mathrm{n}=8)$, decrease eNos activity (388.4 \pm 36.0 vs. $369.6 \pm 43.2$ vs. cpm, $P=\mathrm{NS}, \mathrm{n}=3$ ), or decrease acetylcholine-stimulated cGMP levels ( $0.7 \pm 0.2$ vs. $0.7 \pm 0.1 \mathrm{pmol} \mathrm{cGMP} / \mathrm{mg}$ protein, $P=\mathrm{NS}, \mathrm{n}=4)$ in G6pd-deficient cells suggesting that aldosterone-induced decreased G6pd expression is the cause, and not the consequence, of increased ROS and diminished NO*.

\section{MR blockade or G6pd gene transfer limit G6pd inhibition}

To determine if aldosterone antagonism would prevent aldosterone-mediated inhibition of G6pd, we co-incubated aldosterone-treated $\left(10^{-7} \mathrm{~mol} / \mathrm{l}\right) \mathrm{BAEC}$ with spironolactone (10 $\mu \mathrm{mol} / \mathrm{l})$. Spironolactone prevented the aldosterone-mediated decrease in G6pd expression, 
(Supplementary Fig. 2), activity, and Nadph levels (Supplementary Fig. 6 online). As such, spironolactone also limited ROS accumulation and increased both eNos activity

(Supplementary Fig. 6$)$ and cGMP levels $(0.6 \pm 0.2$ vs. $1.8 \pm 0.2 \mathrm{pmol}$ cGMP/mg protein, $P$ $<0.01, \mathrm{n}=4)$.

We next sought to determine if increased G6pd activity would offer a protective benefit for BAEC exposed to aldosterone. Accordingly, we infected BAEC with an adenoviral vector encoding $G 6 p d(A d G 6 p d)$ at an MOI $=10 \mathrm{pfu} / \mathrm{cell}$ or with an empty vector as a control ${ }^{7}$. Infection of BAEC with AdG6pd increased G6pd expression 310\%, activity 500\%, and Nadph levels $46 \%$ compared to control cells (Supplementary Fig. 7 online). Furthermore, cells that overexpressed G6pd maintained G6pd expression, activity, and Nadph levels (Supplementary Fig. 7) following a $24 \mathrm{~h}$ exposure to aldosterone and were resistant to aldosterone-induced ROS accumulation and inhibition of eNos activity (Supplementary Fig. 7) as compared to control cells.

\section{Aldosterone decreases G6PD activity in vivo}

To determine if our in vitro findings were operative in vivo, we implanted osmotic minipumps to infuse either aldosterone $(50 \mu \mathrm{g} / \mathrm{kg} / \mathrm{d})(\mathrm{n}=40)$ or vehicle $(\mathrm{n}=40)$ for $14 \mathrm{~d}$ in $\mathrm{C} 3 \mathrm{H}$ wild-type mice. Aldosterone infusion increased systolic blood pressure after $4 \mathrm{~d}$, and it remained elevated for the $14 \mathrm{~d}$ treatment period (Fig. 4a). Compared to vehicle-infused mice, aldosterone infusion resulted in a marked increase in serum aldosterone levels at day $14(622 \pm 27$ vs. $4,193 \pm 55 \mathrm{pmol} / \mathrm{l}, P<0.001, \mathrm{n}=12)$ that was associated with a significant decrease in aorta G6pd expression (Fig. 4b), activity (Fig. 4c) and Nadph levels (Fig. 4d).

We next examined aorta ROS using dihydroethidine staining (Fig. 4e). In aortas harvested from aldosterone-infused mice, there was an increase in intima and medial ROS suggesting an increase in both endothelial and vascular smooth muscle oxidant stress that was not observed in vehicle-treated mice; this finding was confirmed with lucigenin $(5 \mu \mathrm{mol} / \mathrm{l})$ chemiluminescence (Fig. 4f). We also found a significant reduction in aorta cGMP levels in aldosterone-infused as compared to vehicle-infused mice (Fig. 4g) despite similar levels of eNos expression (Fig. 4h).

\section{Aldosterone and vascular reactivity}

We evaluated vascular reactivity in vivo to examine the functional consequences of aldosterone-mediated decreased vascular G6pd activity. We utilized intravital videomicroscopy to examine the response of mesenteric resistance vessels to the endothelium-dependent vasodilator acetylcholine $\left(10^{-9}-10^{-5} \mathrm{~mol} / \mathrm{l}\right)$ (Fig. 5a). Compared to vehicle-infused mice $(n=12)$, aldosterone-infused mice $(n=12)$ demonstrated a significant impairment of endothelium-dependent vasodilation. Similarly, vascular reactivity to the endothelium-independent vasodilator, sodium nitroprusside $\left(10^{-9}-10^{-}{ }_{5} \mathrm{~mol} / \mathrm{l}\right)$ was also decreased in aldosterone-infused mice, albeit to a lesser degree than what was observed with acetylcholine (Fig. 5a).

To demonstrate that the aldosterone-mediated inhibition of G6pd activity in vivo resulted in a phenotype similar to what was observed in a genotypic G6pd deficiency we performed the same studies in G6pd-deficient, age-matched, male mice. In vehicle-infused G6pd-deficient mice $(\mathrm{n}=8)$, vascular reactivity to both acetylcholine and sodium nitroprusside was impaired (Fig. 5b) as compared to vehicle-infused wild-type mice (Fig. 5a); administration of aldosterone resulted in no further inhibition of vascular reactivity in G6pd-deficient mice $(\mathrm{n}=8)$.

We next investigated the relative contribution of eNos and endothelium-derived hyperpolarizing factor (Edhf) to vascular reactivity in aldosterone-treated wild-type mice. In 
these studies, mesenteric vessels were superfused with L-NAME ( $1 \mathrm{mmol} / \mathrm{l})$ for $30 \mathrm{~min}$, to inhibit eNos $(\mathrm{n}=5)$, or L-NAME and the potassium channel antagonists TRAM-34 (1 $\mu \mathrm{mol} / \mathrm{l})$ and apamin $(10 \mu \mathrm{mol} / \mathrm{l})(\mathrm{n}=5)$ for $15 \mathrm{~min}$, to inhibit eNos and Edhf, prior to exposure to acetylcholine ${ }^{18}$. In vehicle-infused wild-type mice (Fig. 5c), L-NAME alone decreased the vasodilator response to acetylcholine, suggesting that the majority of observed vasodilation is due to eNos activity. In contrast, in aldosterone-infused wild-type mice (Fig. $5 c)$ there appeared to be a greater contribution to vasodilation by Edhf. Similar observations were made in vehicle-infused G6pd-deficient mice.

\section{MR blockade or gene transfer restores vascular reactivity}

To determine if aldosterone antagonists improve vascular reactivity in vivo by increasing G6pd, we treated aldosterone-infused mice with spironolactone $(n=20)$ or vehicle $(n=20)$. Mice were infused with aldosterone for $7 \mathrm{~d}$, and decreased aorta G6pd activity $(123.8 \pm 12.1$ vs. $57.7 \pm 12.9$ units $/ 6 \mathrm{~min} / \mathrm{mg}$ protein, $P<0.02, \mathrm{n}=10$ ) was confirmed. Spironolactone (20 $\mathrm{mg} / \mathrm{kg} / \mathrm{d}$ ) was then administered in the drinking water during the next $7 \mathrm{~d}$ of aldosterone infusion. In aldosterone-treated mice administered spironolactone, there was a reduction in systolic blood pressure at $14 \mathrm{~d}$ compared to mice that did not receive spironolactone (Fig. 6a). In addition, spironolactone increased aorta G6pd expression (Fig. 6b), activity (Fig. 6c), and Nadph levels (Fig. 6d) leading to a decrease in ROS (Fig. 6e) and an increase in cGMP levels (Fig. 6f). Furthermore, in spironolactone-treated mice, vasodilator responses to acetylcholine and sodium nitroprusside were restored to levels observed in vehicle-infused mice (Fig. 6g).

We next wanted to determine if vascular G6pd overexpression was protective in hyperaldosteronism. In these studies, wild-type mice were injected by tail vein with $5 \times 10^{9}$ plaque forming units of $A d G 6 p d(\mathrm{n}=24)$ or an empty control vector $A d(\mathrm{n}=24)$. Mouse aortic G6pd protein expression, activity, and Nadph levels were increased $370 \%, 340 \%$, and $62 \%$, respectively, $5 \mathrm{~d}$ after infection with $A d G 6 p d$ compared to $A d$-infected mice and remained elevated, although to a lesser extent, up to $18 \mathrm{~d}$ after infection (Supplementary Fig. 8 online). Aldosterone $(50 \mu \mathrm{g} / \mathrm{kg} / \mathrm{d})$ or vehicle infusion via Alzet pump was initiated $5 \mathrm{~d}$ after infection for a $14 \mathrm{~d}$ period. Aldosterone increased systolic blood pressure significantly in $A d$-infected mice as compared to AdG6pd-infected mice (122 \pm 5 vs. $102 \pm 6 \mathrm{mmHg}, P<$ 0.01 ). In aortas isolated from aldosterone-infused control mice, G6pd expression, activity, and Nadph levels were decreased compared to vehicle-infused $A d$-infected mice; in contrast, there was no observed decrease in aldosterone-treated AdG6pd-infected mice (Supplementary Fig. 8). In aldosterone-infused mice, there was an increase in aorta ROS formation, measured by lucigenin $(5 \mu \mathrm{mol} / \mathrm{l})$ chemiluminescence in control mice as compared to AdG6pd-infected mice $\left(3.4 \pm 0.1\right.$ vs. $0.8 \pm 0.05 \mathrm{nmol} / \mathrm{L}^{\bullet} \mathrm{O}_{2}{ }^{-} / 10 \mathrm{~min} / \mathrm{mg}$ protein, $P<0.01, \mathrm{n}=4)$ and a decrease in cGMP levels $(0.32 \pm 0.1$ vs. $0.88 \pm 0.1 \mathrm{pmol} / \mathrm{mg}$ protein, $P<0.01, \mathrm{n}=4$ ) (Supplementary Fig. 8). Vascular reactivity studies revealed attenuated vasodilation to acetylcholine and sodium nitroprusside in $A d$-infected mice, an effect that was not observed in AdG6pd-infected mice (Supplementary Fig. 8).

\section{DISCUSSION}

These studies demonstrate that aldosterone decreases G6pd expression in endothelial cells by increasing cAMP levels to activate PkA, which, in turn, upregulates Crem expression to inhibit Creb-DNA binding and limit transcription of G6pd. At a cellular level, decreased G6pd expression results in a concomitant decrease in Nadph levels to increase endothelial ROS and decrease bioavailable $\mathrm{NO}^{*}$, similar to what is observed in G6pd-deficient cells. In vitro, PkA inhibition or aldosterone antagonism preserves G6pd expression to prevent the aforementioned adverse sequelae of aldosterone. Similarly, overexpression of G6pd provides resistance to aldosterone-mediated increased ROS and diminished bioavailable 
NO* We confirmed these findings in vivo by demonstrating that pathophysiologically relevant ${ }^{19-21}$ levels of plasma aldosterone in wild-type mice are associated with decreased vascular G6pd expression, increased ROS, and decreased NO ${ }^{\bullet}$ similar to what is observed in G6pd-deficient mice. Functionally, elevated levels of aldosterone impaired endotheliumdependent vascular reactivity to a greater extent than endothelium-independent vasodilation. We also found that MR blockade restored vascular reactivity by preventing decreased G6pd expression, and that overexpression of G6pd is protective in states of hyperaldosteronism.

In our studies, we treated cells with relatively high concentrations of aldosterone; however, these concentrations were selected as aldosterone levels as high as $10^{-7} \mathrm{~mol} / \mathrm{l}$ have been reported in patients with congestive heart failure ${ }^{19-21}$. Furthermore, we confirmed our in vitro findings using pathophysiologically relevant levels of aldosterone in vivo, suggesting that our in vitro studies mimic the in vivo environment. In aldosterone-infused mice, there was an observed increase in plasma aldosterone levels of $574 \%$ as compared to vehicleinfused mice. This is well within the range achieved when comparing plasma aldosterone levels in healthy subjects with those of congestive heart failure patients; under these circumstances, plasma aldosterone levels have been reported to be increased up to $1900 \%{ }^{21}$.

Our studies implicate activation of PKA and PKA-mediated upregulation of CREM to inhibit CREB driven transcription as a mechanism by which hyperaldosteronism decreases G6PD expression. This is not surprising as earlier studies have shown that PKA activation modulates transcriptional functions of the $\mathrm{MR}^{22}$ and that aldosterone-mediated activation of MR may also repress gene transcription ${ }^{23}$, which is in line with the findings that we describe here; however, in these studies, the role of CREM-mediated inhibition of CREB-DNA binding activity was not investigated. Under basal conditions, decreased CREB activity by CREM repressor isoforms is a transient phenomenon, while persistent expression has been associated with pathophysiological consequences ${ }^{24}$. CREM is a recognized target protein of PKA and studies have shown that inhibition of PKA results in inhibition of CREM expression ${ }^{25}$. Interestingly, prolonged increased expression of the Crem repressor isoform has been implicated in the inhibition of gene transcription in glucocorticoid-treated rats ${ }^{26}$ and angiotensin II-treated cardiomyocytes ${ }^{27}$. We now show that hyperaldosteronism similarly leads to a persistent increase in CREM expression and, thereby, inhibition of G6PD expression.

Accumulating evidence suggests that the adverse effects of aldosterone on vascular reactivity result from an aldosterone-induced vasculopathy characterized by increased ROS and decreased $\mathrm{NO}^{\bullet}$ levels ${ }^{5}$. Similar to our findings, other investigators have reported an increase in ROS levels in aldosterone $\left(10^{-9}-10^{-7} \mathrm{~mol} / \mathrm{L}\right)$-treated human umbilical vein endothelial cells that was abrogated by MR blockade ${ }^{28}$. Ex vivo, myocardial endothelial cells isolated from aldosterone-infused rats were shown to have increased indices of oxidant stress as demonstrated by enhanced peroxynitrite formation ${ }^{29}$.

The effects of aldosterone on eNOS activity have been less well characterized. In human umbilical vein endothelial cells exposed to aldosterone $\left(10^{-9}-10^{-7} \mathrm{~mol} / \mathrm{l}\right)$ for $16 \mathrm{~h}$ and stimulated with vascular endothelial growth factor, cGMP levels and eNOS dimer/monomer ratios were decreased akin to our results. These findings were attributed to decreased levels of 5,6,7,8-tetrahydrobiopterin ${ }^{28}$, an eNOS cofactor whose levels are maintained by adequate G6PD activity and NADPH stores. In contrast, in a rat congestive heart failure model, aorta eNos expression was decreased, an effect that was corrected by eplerenone ${ }^{30}$. In our studies, we found similar levels of eNos expression in aortas from vehicle-treated and aldosteroneinfused mice; however, eNos activity was decreased only in aldosterone-treated animals. These differences may be explained by the duration of treatment as well as differences in the models used to create a state of secondary hyperaldosteronism. 
Our studies found that aldosterone antagonism restored vascular reactivity by increasing G6pd expression. It has been suggested that changes in blood pressure may modulate this response; however, comparative studies in G6pd-deficient mice suggest that changes in G6pd expression, and not blood pressure, mediate the effects of MR blockade. In fact, in $\mathrm{C} 3 \mathrm{H}$ wild-type mice infused with angiotensin II $(0.6 \mathrm{mg} / \mathrm{kg} / \mathrm{d})$ for $6 \mathrm{~d}$, systolic blood pressure was increased yet aorta G6pd protein levels remained similar to that observed in vehicle-infused mice ${ }^{31}$. Furthermore, vascular gene transfer of $G 6 p d$ prevented an aldosterone-mediated increase in blood pressure. These findings are supported further by clinical studies that have shown that impaired vascular reactivity is restored in patients with elevated plasma aldosterone levels treated with aldosterone antagonists independent of changes in blood pressure ${ }^{32-34}$. These studies suggest that the beneficial effects of aldosterone antagonism result from a mechanism that does not involve changes in systemic blood pressure, analogous to what we observed.

Our studies may also explain the observed lack of benefit of aldosterone antagonism in patients with diabetes mellitus. Studies in patients with type 2 diabetes mellitus treated with spironolactone revealed no improvement in endothelial function ${ }^{35}$. One potential explanation for this finding is that hyperglycemia associated with diabetes may decrease G6PD activity by a mechanism other than activation of the MR. Studies performed in vitro and in animal models suggest that this hypothesis has merit; BAEC exposed to elevated concentrations of glucose demonstrate decreased G6pd activity ${ }^{36}$, and, in a diabetic rat model, renal G6pd activity was decreased significantly as compared to non-diabetic rats ${ }^{10}$.

Interestingly, our studies revealed a defect in endothelium-dependent and, to a lesser extent, endothelium-independent, vascular reactivity owing to a decrease in eNos activity. Similarly, transgenic mice that overexpress aldosterone synthase in the heart also exhibit both impaired endothelium-dependent and endothelium-independent vascular reactivity; however, the mechanism by which this occurred remains unknown ${ }^{37}$. These findings correlate with observations made in a preliminary clinical study that investigated brachial artery vascular reactivity in G6PD-deficient patients. In this study, 18 healthy G6PDdeficient African-American subjects with the A326G mutation were found to have impaired flow-mediated dilation ${ }^{38}$. While the goal of our study was to examine the effects of aldosterone on G6pd activity in the vascular endothelium, we have previously demonstrated that vascular smooth muscle cells with deficient G6pd activity have increased ROS accumulation ${ }^{39}$. This suggests that aldosterone may also influence G6pd activity in vascular smooth muscle cells to modulate vascular reactivity in addition to its effects on the endothelium.

Our results suggest a novel mechanism by which hyperaldosteronism impairs vascular reactivity consonant with the concept of aldosterone-induced vasculopathy characterized by increased oxidant stress and decreased $\mathrm{NO}^{\bullet}$ bioavailability. Aldosterone-mediated inhibition of G6pd activity results in a G6pd-deficient phenotype in the vascular endothelium in the absence of a genetic cause for deficient G6pd activity. This induced phenotype is reversible with MR blockade or vascular overexpression of G6pd, resulting in resistance to the adverse sequelae of hyperaldosteronism in the vasculature. Our findings suggest further that future therapeutic intervention(s) to modulate G6pd activity may serve as a strategy to ameliorate vascular dysfunction associated with hyperaldosteronism.

\section{METHODS}

(Supplementary Methods online) 


\section{Cell culture}

Bovine aortic endothelial cells (BAEC) (Cambrex) or human coronary artery endothelial cells (Cambrex) were grown to confluence and treated with aldosterone $\left(10^{-9}-10^{-7} \mathrm{~mol} / \mathrm{l}\right)$ (Steraloids); aldosterone was dissolved in dimethylsulfoxide $(10 \mathrm{nmol} / \mathrm{l})$, which served as the vehicle control. In selected studies, cells were co-incubated with spironolactone (10 $\mu \mathrm{mol} / \mathrm{l})$ (Sigma-Aldrich).

To increase G6pd expression, a recombinant adenovirus encoding rat $G 6 p d$ cDNA under direction of the CMV promoter, $A d G 6 p d$, or an empty viral vector, $A d$, was constructed and utilized as previously described ${ }^{7,17,40}$.

To isolate endothelial cells from aortas of $\mathrm{C} 3 \mathrm{H}$ wild-type or G6pd-deficient mice, aortas were harvested from mice age 4-6 weeks, digested with collagenase (Worthington), and subjected to a double selection process by incubation with CD31 (Santa Cruz

Biotechnology) and VE-cadherin (Research Diagnostics) monoclonal antibody-coated magnetic microbeads (Dynal Biotech). Cells were found to be $>98 \%$ pure by uptake of DiIAc-LDL (Molecular Probes) ${ }^{41}$.

\section{G6pd activity and Nadph levels}

G6pd activity and Nadph levels were determined according to previously published methods ${ }^{6,42}$.

\section{Immunoblotting}

Proteins were size-fractionated electrophoretically using SDS-polyacrylamide gel electrophoresis and transferred to PVDF membranes. The membranes were incubated with antibodies to G6pd (Bethyl Laboratories), eNos (Transduction Laboratories), Creb, phospho-Creb (Cell Signaling Technology), or Crem (Santa Cruz), and visualized utilizing the ECL detection system (Amersham). To evaluate eNos monomer-dimer formation, low temperature PAGE was performed according to previously published methods ${ }^{15,16}$.

\section{RNA isolation, G6pd cDNA generation, and northern hybridization}

Total RNA was prepared using the RNeasy mini kit (Qiagen) and cDNA was generated using the SuperScript ${ }^{\mathrm{TM}}$ III One-Step RT-PCR System (Invitrogen). The following primer pairs were used: $G 6 p d$ : forward (5'-ACGATGACACTGCCTCCTACAAGC-3'), reverse ( $5^{\prime}$-GCTCTTTGAAGGTGAGAATGACGC-3'); Crem: forward (5' CCTCCACCAGGTGCTACAT-3'), reverse (5'-AGCAGCTTCCCTGTTTTTCA-3'); Gapdh: forward (5'-GGGTCATCATCTCTGCACCT-3'), reverse (5' GGTCATAAGTCCCTCCACGA-3'). DIG-High Prime DNA Labeling and Detection Starter Kit II (Roche) was used to label G6pd, Crem, or Gapdh cDNA fragments with digoxigenin for use as probes. For Northern blot analysis, $5 \mu$ gtotal RNA was fractionated on $1.2 \%$ formaldehyde-agarosegels and transferred onto positively charged nylon membranes (Roche). Hybridization and detection of mRNA was performed using a Digoxigenin Luminescent Detection Kit (Roche) according to manufacturer's instructions.

\section{Quantitative real-time PCR}

Quantitative real-time PCR was performed using 20X TaqMan® G6pd or Gapdh Gene Expression Assay (Applied Biosystems) and run on Applied Biosystems 7700. Quantitation of data was performed using the comparative $\mathrm{C}_{\mathrm{T}}\left(\Delta \Delta \mathrm{C}_{\mathrm{T}}\right)$ method using Gapdh gene expression as an endogenous reference. 


\section{cAMP and cGMP levels}

Levels of cAMP or cGMP levels were quantitated using an enzyme immunoassay kit

(Cayman) according to manufacturer's instructions.

\section{Protein kinase A activity}

Protein kinase A activity was measured using PepTag ${ }^{\circledR}$ Non-Radioactive cAMP-Dependent Protein Kinase Assay (Promega) according to the manufacturer's instructions.

\section{Nuclear run-on assay}

Nuclear preparations were isolated using the $\mathrm{BD}^{\mathrm{TM}}$ TransFactor Nuclear Extraction Kit (Clontech) according to manufacturer's instructions. Nuclearrun-on assays were performed according to previously published methods ${ }^{43}$.

\section{Electrophoretic mobility shift assay}

Nuclear preparations were isolated using the BD TransFactor Nuclear Extraction Kit (Clontech) according to manufacturer's instructions. An oligonucleotide probe was biotinlabeled with Biotin 3' End DNA Labeling kit (Pierce). The probe contained the Creb binding site (-889--881) from the G6pd promoter and was included using the oligonucleotides: forward $5^{\prime}$-CAGAAACAGTATGACGATAGGCAGAT- $3^{\prime}$ and reverse $5^{\prime}$-ATCTGCCTATCGTCATACTGTTTCTG-3'. Electrophoretic mobility shift assays were performed using the LightShift ${ }^{\circ}$ Chemiluminescent EMSA kit (Pierce) according to manufacturer's instructions.

\section{Chromatin immunoprecipitation assay}

The chromatin immunoprecipitation assay was performed using the QuikChIP assay (Imgenex) according to manufacturer's instructions. The G6PD primers used for PCR were: forward $5^{\prime}$-TGACCTCCGTGCTATTCCTC- $3^{\prime}$ and reverse $5^{\prime}$ -

ACCAAACTTGACTGCGCTCT- $3^{\prime}$. As a specificity control, the $\beta$-actin promoter was similarly amplified using the primers: forward $5^{\prime}$-GTAGAGCCCACCTTCCTTCC- $3^{\prime}$ and reverse $5^{\prime}$-AGAGCGAGAGCGAGATTGAG-3'.

\section{Sgk activity}

Sgk activity was measured in cell homogenates using the QTL Lightspeed® SGK-1 Kinase Activity assay (QTL Biosystems) according to manufacturer's instructions.

\section{Dichlorodihyrdofluorescein fluorescence}

Non-specific cellular reactive oxygen species accumulation was measured as previously described using $20 \mu \mathrm{M}$ 6-carboxy- $2^{\prime}-7^{\prime}$-dichlorodihydrofluorescein diacetate di(acetoxymethyl) ester (Molecular Probes) ${ }^{7}$.

\section{GSH/GSSG levels}

The ratio of glutathione (GSH)/glutathione disulfide (GSSG) was measured utilizing the Bioxytech ${ }^{\circledR}$ GSH-GSSG-412 ${ }^{\mathrm{TM}}$ enzymatic method (OXIS) according to the manufacturer's instructions.

\section{eNos activity}

eNos activity was measured in intact cells without the addition of exogenous cofactors as previously described ${ }^{44}$. In select studies, eNos activity was measured in cell homogenates with the addition of exogenous cofactors according to previously published methods ${ }^{6,7}$. 


\section{In vivo aldosterone infusion}

C3H wild-type male mice were obtained from Charles River and entered into studies at age 12-16 weeks. G6pd-deficient mice were maintained in a colony at Harvard Medical School and have been characterized previously ${ }^{17}$. The animals were fed standard chow, kept on $1 \%$ $\mathrm{NaCl}$ in the drinking water, and handled following $\mathrm{NIH}$ guidelines. All procedures were approved by the Institutional Animal Care and Use Committee at BostonUniversity Medical Center and Brigham and Women's Hospital, Harvard Medical School. Alzet minipumps (Alza, Model 1002) were implanted and mice infused for $14 \mathrm{~d}$ with aldosterone $(50 \mu \mathrm{g} / \mathrm{kg} /$ d ${ }^{45}$. In selected studies, mice were treated with spironolactone, which was added to the drinking water $(20 \mathrm{mg} / \mathrm{kg} / \mathrm{d})^{46}$.

\section{Blood pressure}

Baseline blood pressure (BP) and heart rate were determined using tail-cuff measurements (Visitech BP-2000, Visitech Systems).

\section{Plasma aldosterone}

Plasma aldosterone levels were measured by enzyme immunoassay (Cayman).

\section{Aorta ROS generation}

Aorta rings were incubated with lucigenin $(5 \mu \mathrm{mol} / \mathrm{L})$ and chemiluminescence was measured using a luminometer (TI-300, Turner Industries) ${ }^{47}$. As a second measure of ROS, unfixed aortas were immediately frozen, sectioned, and incubated with $20 \mu \mathrm{mol} /$ ldihydroethidine (Molecular Probes). Ethidium fluorescence was detected with a Zeiss LSM 510 microscope equipped with a krypton/argon laser ${ }^{48}$.

\section{Vascular reactivity}

Vascular reactivity of mesenteric arterioles was assessed by intravital videomicroscopy as previously described ${ }^{47}$. The response was expressed as percent change in vessel diameter compared with baseline.

\section{Statistical analysis}

Continuous data were expressed as mean \pm SEM. Comparison between groups was performed by Student's paired two-tailed $t$ test. Two-way ANOVA was used to examine differencesin response to treatments between groups, with post hoc analysis performed by the method of Student-Newman-Keuls. A $p$ value of $<0.05$ was considered significant.

\section{Supplementary Material}

Refer to Web version on PubMed Central for supplementary material.

\section{Acknowledgments}

This work was supported in part by National Institutes of HealthGrants HL61828, HL58976, HL55993, and HV28178 (to J. L.), HL04399, HL081110, and a Grant-in-Aid from the American Heart Association (to J.A.L.), HL067297, HL071775and HL073756 (to R.L.), and DK053480-05 (to R.S.).

\section{References}

1. Blacher J, et al. Association between increased plasma levels of aldosterone and decreased systemic arterial compliance in subjects with essential hypertension. Am J Hypertens. 1997; 10:1326-1334. [PubMed: 9443767] 
2. Duprez DA, et al. Inverse relationship between aldosterone and large artery compliance in chronically treated heart failure patients. Eur Heart J. 1998; 19:1371-1376. [PubMed: 9792263]

3. Weber KT. Aldosteronism revisited: perspectives on less well-recognized actions of aldosterone. J Lab Clin Med. 2003; 142:71-82. [PubMed: 12960953]

4. Farquharson CA, Struthers AD. Spironolactone increases nitric oxide bioactivity, improves endothelial vasodilator dysfunction, and suppresses vascular angiotensin I/angiotensin II conversion in patients with chronic heart failure. Circulation. 2000; 101:594-597. [PubMed: 10673249]

5. Struthers AD. Aldosterone-induced vasculopathy. Mol Cell Endocrinol. 2004; 217:239-241. [PubMed: 15134823]

6. Leopold JA, Cap A, Scribner AW, Stanton RC, Loscalzo J. Glucose-6-phosphate dehydrogenase deficiency promotes endothelial oxidant stress and decreases endothelial nitric oxide bioavailability. Faseb J. 2001; 15:1771-1773. [PubMed: 11481225]

7. Leopold JA, Zhang YY, Scribner AW, Stanton RC, Loscalzo J. Glucose-6-phosphate dehydrogenase overexpression decreases endothelial cell oxidant stress and increases bioavailable nitric oxide. Arteriosclerosis, Thrombosis, and Vascular Biology. 2003; 23:411-417.

8. Criss WE, McKerns KW. Inhibitors of the catalytic activity of bovine adrenal glucose-6- phosphate dehydrogenase. Biochim Biophys Acta. 1969; 184:486-494. [PubMed: 4390358]

9. Liew CC, Gornall AG. Effects of aldosterone on blood pressure and glucose-6-phosphate dehydrogenase activity of heart muscle. Can J Physiol Pharmacol. 1969; 47:193-197. [PubMed: 4389001]

10. Xu Y, Osborne BW, Stanton RC. Diabetes causes inhibition of glucose-6-phosphate dehydrogenase via activation of PKA, which contributes to oxidative stress in rat kidney cortex. Am J Physiol Renal Physiol. 2005; 289:F1040-1047. [PubMed: 15956780]

11. Guo L, Zhang Z, Green K, Stanton RC. Suppression of interleukin-1 beta-induced nitric oxide production in RINm5F cells by inhibition of glucose-6-phosphate dehydrogenase. Biochemistry. 2002; 41:14726-14733. [PubMed: 12475221]

12. Macho B, Sassone-Corsi P. Functional analysis of transcription factors CREB and CREM. Methods in Enzymology. 2003; 370:396-415. [PubMed: 14712663]

13. Zhang X, et al. Genome-wide analysis of cAMP-response element binding protein occupancy, phosphorylation, and target gene activation in human tissues. Proceedings of the National Academy of Sciences. 2005; 102:4459-4464.

14. Manna PR, et al. Regulation of steroidogenesis and the steroidogenic acute regulatory protein by a member of the cAMP response-element binding protein family. Molecular Endocrinology. 2002; 16:184-199. [PubMed: 11773448]

15. Klatt $\mathrm{P}$, et al. Characterization of heme-deficient neuronal nitric-oxide synthase reveals a role for heme in subunit dimerization and binding of the amino acid substrate and tetrahydrobiopterin. $\mathbf{J}$ Biol Chem. 1996; 271:7336-7342. [PubMed: 8631754]

16. Cai S, Khoo J, Mussa S, Alp NJ, Channon KM. Endothelial nitric oxide synthase dysfunction in diabetic mice: importance of tetrahydrobiopterin in eNOS dimerisation. Diabetologia. 2005; 48:1933-1940. [PubMed: 16034613]

17. Leopold JA, et al. Glucose-6-phosphate dehydrogenase modulates vascular endothelial growth factor-mediated angiogenesis. J Biol Chem. 2003; 278:32100-32106. [PubMed: 12777375]

18. Ding H, et al. Endothelial dysfunction in the streptozotocin-induced diabetic apoE-deficient mouse. British J of Pharm. 2005; 146:1110-1118.

19. Rousseau MF, et al. Beneficial neurohormonal profile of spironolactone in severe congestive heart failure: results from the RALES neurohormonal substudy. J Am Coll of Card. 2002; 40:15961601.

20. Silvestre JS, et al. Myocardial production of aldosterone and corticosterone in the rat. Physiological regulation. J Biol Chem. 1998; 273:4883-4891. [PubMed: 9478930]

21. Weber KT. Aldosterone in congestive heart failure. N Engl J Med. 2001; 345:1689-1697. [PubMed: 11759649]

22. Massaad C, Houard N, Lombes M, Barouki R. Modulation of human mineralocorticoid receptor function by protein kinase A. Molecular Endocrinology. 1999; 13:57-65. [PubMed: 9892012] 
23. Booth RE, Johnson JP, Stockand JD. Aldosterone. Adv Physiol Educ. 2002; 26:8-20. [PubMed: 11850323]

24. Mioduszewska B, Jaworski J, Kaczmarek L. Inducible cAMP early repressor (ICER) in the nervous system--a transcriptional regulator of neuronal plasticity and programmed cell death. $\mathrm{J}$ of Neurochem. 2003; 87:1313-1320. [PubMed: 14713288]

25. Boissel JP, Bros M, Schrock A, Godtel-Armbrust U, Forstermann U. Cyclic AMP-mediated upregulation of the expression of neuronal NO synthase in human A673 neuroepithelioma cells results in a decrease in the level of bioactive NO production: analysis of the signaling mechanisms that are involved. Biochemistry. 2004; 43:7197-7206. [PubMed: 15170357]

26. Shepard JD, Liu Y, Sassone-Corsi P, Aguilera G. Role of glucocorticoids and cAMP-mediated repression in limiting corticotropin-releasing hormone transcription during stress. J Neurosci. 2005; 25:4073-4081. [PubMed: 15843609]

27. Ding B, et al. A positive feedback loop of phosphodiesterase 3 (PDE3) and inducible cAMP early repressor (ICER) leads to cardiomyocyte apoptosis. Proceedings of the National Academy of Sciences. 2005; 102:14771-14776.

28. Nagata D, et al. Molecular mechanism of the inhibitory effect of aldosterone on endothelial NO synthase activity. Hypertension. 2006; 48:165-171. [PubMed: 16754797]

29. Sun Y, et al. Aldosterone-induced inflammation in the rat heart: role of oxidative stress. Am J Pathol. 2002; 161:1773-1781. [PubMed: 12414524]

30. Schafer A, et al. Addition of the selective aldosterone receptor antagonist eplerenone to ACE inhibition in heart failure: effect on endothelial dysfunction. Cardiovasc Res. 2003; 58:655-662. [PubMed: 12798439]

31. Matsui R, et al. Glucose-6 phosphate dehydrogenase deficiency decreases the vascular response to angiotensin II. Circulation. 2005; 112:257-263. [PubMed: 15998684]

32. Nishizaka MK, Zaman MA, Green SA, Renfroe KY, Calhoun DA. Impaired endotheliumdependent flow-mediated vasodilation in hypertensive subjects with hyperaldosteronism. Circulation. 2004; 109:2857-2861. [PubMed: 15173035]

33. Abiose AK, et al. Effect of spironolactone on endothelial function in patients with congestive heart failure on conventional medical therapy. Am J Card. 2004; 93:1564-1566. [PubMed: 15194040]

34. Macdonald JE, Kennedy N, Struthers AD. Effects of spironolactone on endothelial function, vascular angiotensin converting enzyme activity, and other prognostic markers in patients with mild heart failure already taking optimal treatment. Heart. 2004; 90:765-770. [PubMed: 15201246]

35. Davies JI, Band M, Morris A, Struthers AD. Spironolactone impairs endothelial function and heart rate variability in patients with type 2 diabetes. Diabetologia. 2004; 47:1687-1694. [PubMed: 15365622]

36. Zhang Z, Apse K, Pang J, Stanton RC. High glucose inhibits glucose-6-phosphate dehydrogenase via cAMP in aortic endothelial cells. J Biol Chem. 2000; 275:40042-40047. [PubMed: 11007790]

37. Garnier A, et al. Cardiac specific increase in aldosterone production induces coronary dysfunction in aldosterone synthase-transgenic mice. Circulation. 2004; 110:1819-1825. [PubMed: 15364804]

38. Forgione MA, et al. The A326G (A+) Variant of the Glucose-6-Phosphate Dehydrogenase Gene is Associated with Endothelial Dysfunction in African Americans. J Am Coll of Card. 2003; 41:249A.

39. Leopold JA, Loscalzo J. Cyclic strain modulates resistance to oxidant stress by increasing G6PDH expression in smooth muscle cells. Am J Physiol Heart Circ Physiol. 2000; 279:H2477-2485. [PubMed: 11045985]

40. Zhang YY, et al. Expression of 5-lipoxygenase in pulmonary artery endothelial cells. Biochem J. 2002; 361:267-276. [PubMed: 11772398]

41. Dong QG, et al. A general strategy for isolation of endothelial cells from murine tissues. Characterization of two endothelial cell lines from the murine lung and subcutaneous sponge implants. Arteriosclerosis, Thrombosis, and Vascular Biology. 1997; 17:1599-1604.

42. Zhang Z, Yu J, Stanton RC. A method for determination of pyridine nucleotides using a single extract. Anal Biochem. 2000; 285:163-167. [PubMed: 10998277] 
43. Zhang MX, et al. Regulation of endothelial nitric oxide synthase by small RNA. Proceedings of the National Academy of Sciences. 2005; 102:16967-16972.

44. Uittenbogaard A, Shaul PW, Yuhanna IS, Blair A, Smart EJ. High density lipoprotein prevents oxidized low density lipoprotein-induced inhibition of endothelial nitric-oxide synthase localization and activation in caveolae. J Biol Chem. 2000; 275:11278-11283. [PubMed: 10753938]

45. Hou J, Speirs HJ, Seckl JR, Brown RW. Sgk1 gene expression in kidney and its regulation by aldosterone: spatio-temporal heterogeneity and quantitative analysis. J Am Soc Nephrol. 2002; 13:1190-1198. [PubMed: 11961006]

46. Michel F, et al. Aldosterone enhances ischemia-induced neovascularization through angiotensin IIdependent pathway. Circulation. 2004; 109:1933-1937. [PubMed: 15078792]

47. Eberhardt RT, et al. Endothelial dysfunction in a murine model of mild hyperhomocyst(e)inemia. J Clin Invest. 2000; 106:483-491. [PubMed: 10953023]

48. Virdis A, et al. Effect of hyperhomocystinemia and hypertension on endothelial function in methylenetetrahydrofolate reductase-deficient mice. Arteriosclerosis, Thrombosis, and Vascular Biology. 2003; 23:1352-1357. 


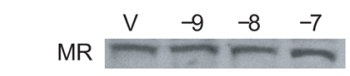

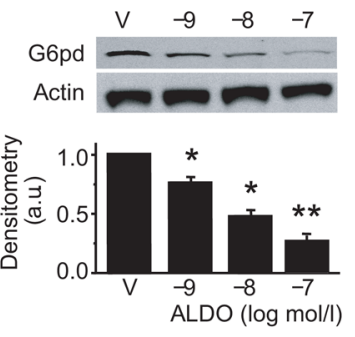

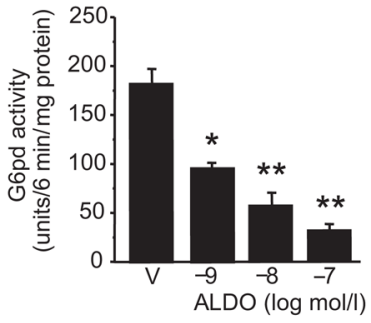

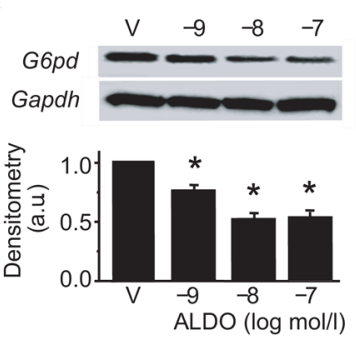

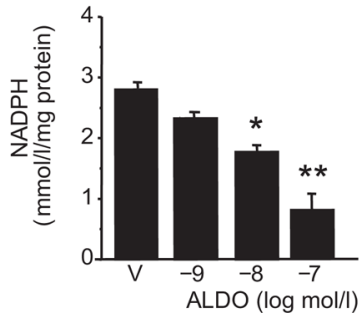

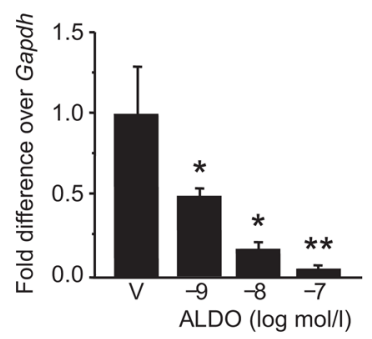

Figure 1. Aldosterone decreases G6pd expression and activity BAEC were treated with aldosterone (ALDO) or vehicle (V) for $24 \mathrm{~h}$ and the effect of ALDO on (a) mineralocorticoid receptor (MR) expression, (b) G6pd protein expression, and G6pd mRNA levels by (c) Northern blotting and (d) quantitative real-time PCR (n=4) was assessed. Concomitant changes in $(\mathbf{e})$ G6PD activity $(\mathrm{n}=8)$ and $(\mathbf{f})$ NADPH levels $(\mathrm{n}=4)$

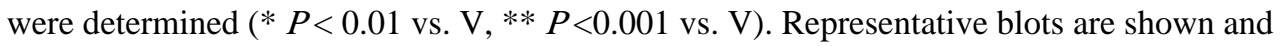
densitometry was performed on a minimum of three blots and reported as arbitrary units (a.u.). Data represent mean \pm SEM. 

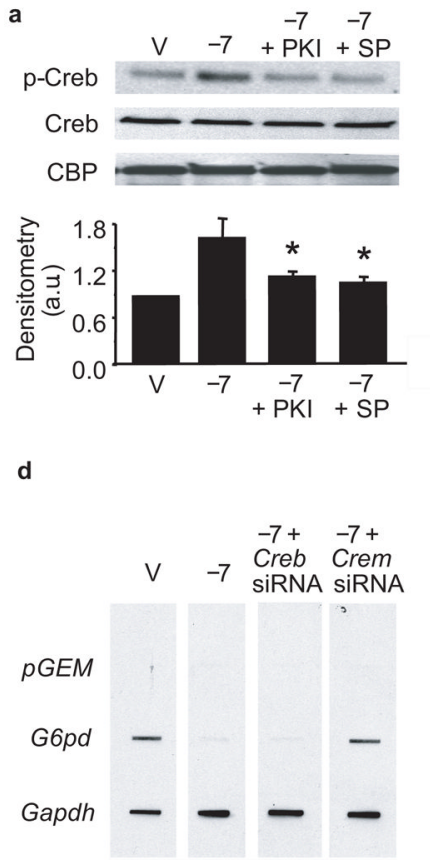

b
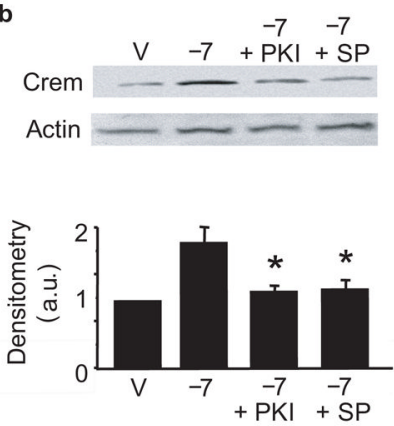

e

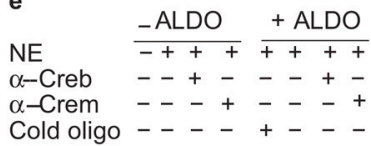

Cold oligo $-\ldots+\ldots+\ldots$

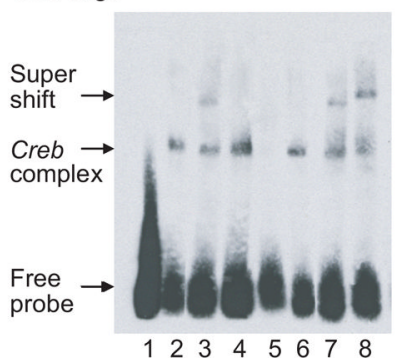

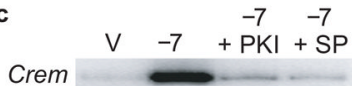

Gapdh
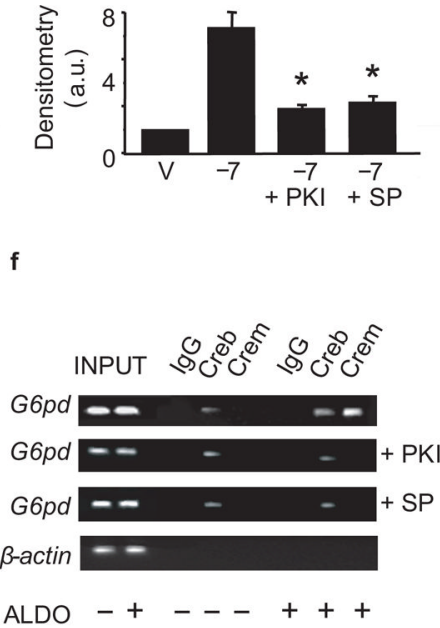

Figure 2. Aldosterone decreases G6pd by increasing Crem

BAEC were treated with aldosterone (ALDO) or vehicle (V) for $24 \mathrm{~h}$ in the presence or absence of the PkA inhibitor, PKI, or spironolactone (SP), and (a) cyclic AMP response element-binding protein (Creb), phospho-Creb, and Creb binding protein (CBP) expression were determined ( $* P<0.05$ vs. -7$)$. (b) Cyclic AMP response element modulator (Crem) protein expression and (c) mRNA levels by Northern blotting were determined $(* P<0.01$ vs. -7). (d) Nuclear run-on studies demonstrate the rate of transcription of G6pd in BAEC with decreased expression of Creb or Crem. Plasmid DNA, $p G E M$, served as a negative control and Gapdh as a loading reference. ( ${ }^{*} P<0.001$ vs. V, n $\left.=4\right)$. (e) Electrophoretic mobility shift assays $(n=4)$ were performed using an oligonucleotide containing the CREB/ CREM binding site sequence from the G6PD promoter $\left(5^{\prime}\right.$ -

CAGAAACAGTATGACGATAGGCAGAT- $3^{\prime}$ ) and nuclear extract from V-treated (lane 2) or ALDO-treated cells (lane 6). Supershift assays were carried out with antibodies to CREB (lanes 3 and 7) or CREM (lanes 4 and 8). A competition assay (lane 5) was performed with 100-fold excess of cold oligonucleotide. (f) Chromatin immunoprecipitation $(n=4)$ of lysates using antibodies to CREB or CREM was followed by PCR amplification of the CREB/CREM binding site in the G6PD promoter; immunoglobulin G (IgG) and amplification of the $\beta$-actin promoter by PCR served as controls. Densitometry on a minimum of three blots is reported as arbitrary units (a.u.). Data represent mean \pm SEM. 


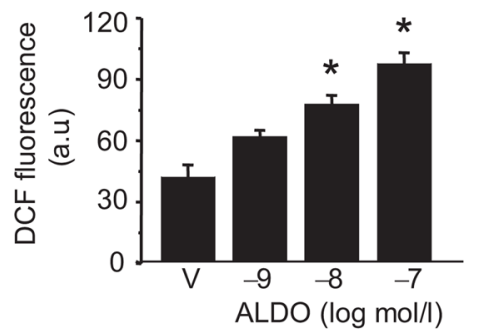

b

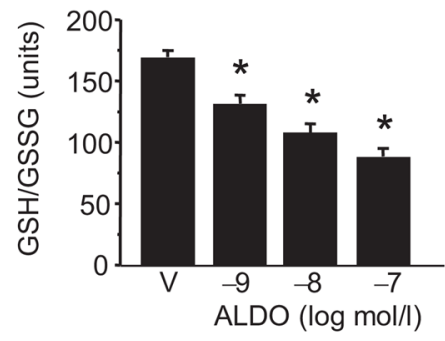

c

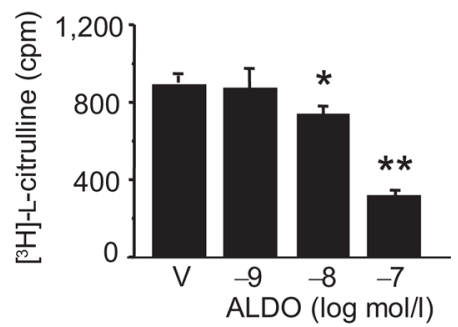

d

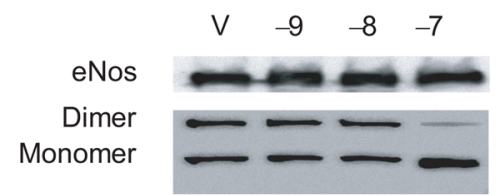

e

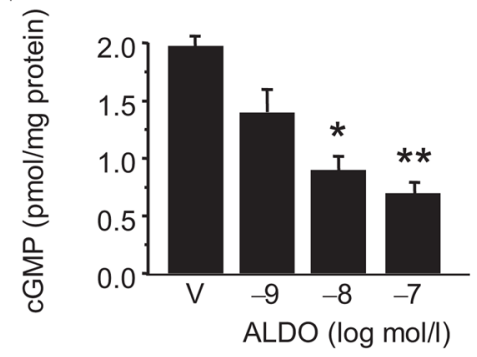

Figure 3. Aldosterone increases endothelial cell oxidant stress and decreases bioavailable NO (a) Reactive oxygen species accumulation was measured by 6-carboxy-2' $-7^{\prime}$ dichlorodihydrofluorescein diacetate (DCF) fluorescence in BAEC treated with aldosterone (ALDO) or vehicle (V) for $24 \mathrm{~h}$ and reported as arbitrary units (a.u.) ( $* P<0.01 \mathrm{vs.} \mathrm{V}, \mathrm{n}=$ 8). (b) The corresponding reduced glutathione (GSH)/oxidized glutathione (GSSG) ratio was measured ( $* P<0.05$ vs. $\mathrm{V}, \mathrm{n}=6)$. (c) eNos activity was determined in intact endothelial cells in the absence of exogenous cofactors $(* P<0.05 \mathrm{vs}$. $\mathrm{V}$, $* * P<0.001 \mathrm{vs}$. V, $\mathrm{n}=6$ ). (d) eNos protein levels were examined; dimer-monomer levels were determined by low temperature gel electrophoresis, and (e) levels of bioactive $\mathrm{NO}^{\bullet}$ were determined by measuring cGMP in cells stimulated with bradykinin $(5 \mu \mathrm{mol} / \mathrm{L})(* P<0.01 \mathrm{vs}$. V, $* * P<$ 0.005 vs. $\mathrm{V}, \mathrm{n}=8$ ). Representative blots are shown. Data represent mean \pm SEM. 


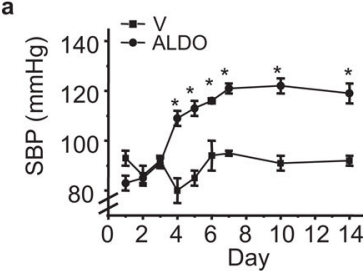

b

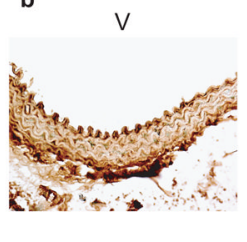

e
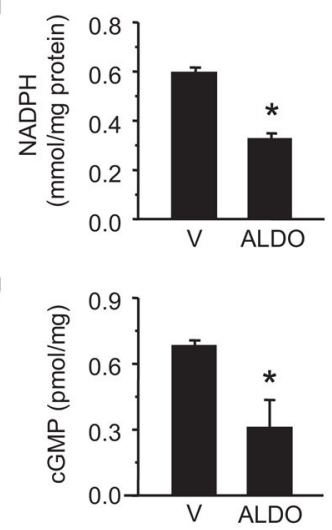
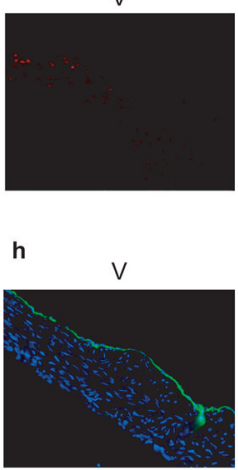
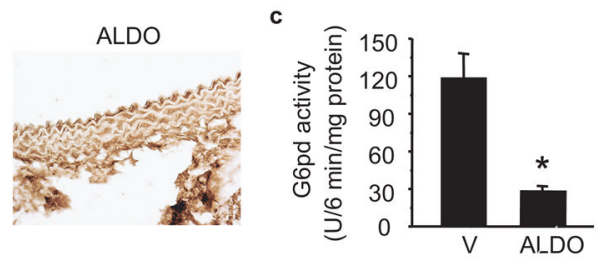

ALDO

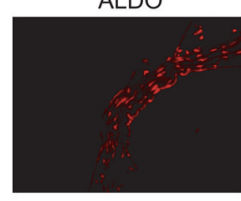

ALDO

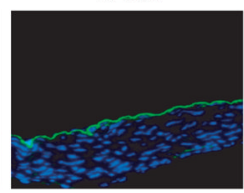

Figure 4. Aldosterone and G6pd activity in vivo

C3H wild-type mice were infused with aldosterone ( $50 \mu \mathrm{g} / \mathrm{kg} / \mathrm{day}$ ) (ALDO) or vehicle (V) via Alzet minipump for $14 \mathrm{~d}$ and (a) systolic blood pressure (SBP) was measured by tail cuff ( $* P<0.001$ vs. $\mathrm{V} ; \mathrm{n}=40$ per treatment group). After $14 \mathrm{~d}$ of aldosterone infusion, aortas were harvested and (b) G6pd expression was examined by immunohistochemistry; and (c) G6pd activity and (d) Nadph levels were measured in tissue homogenates $(* P<0.001$ vs. V, $\mathrm{n}=12$ ). (e) Aorta reactive oxygen species formation was examined by dihydroethidine fluorescence and (f) lucigenin $(5 \mu \mathrm{mol} / \mathrm{L})$ chemiluminescence $(* P<0.001$ vs. $\mathrm{V}, \mathrm{n}=12)$. (g) Levels of bioavailable $\mathrm{NO}^{*}$ were assessed by cGMP levels $(* P<0.01$ vs. $\mathrm{V}, \mathrm{n}=12)$. (h) eNos expression was examined in the aorta by immunofluorescence. Representative sections are shown; all sections magnified 200X. Data represent mean \pm SEM. 


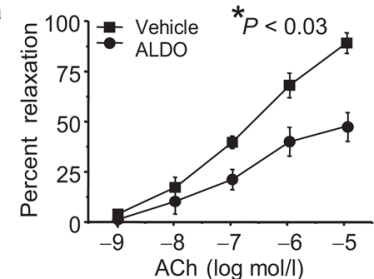

b
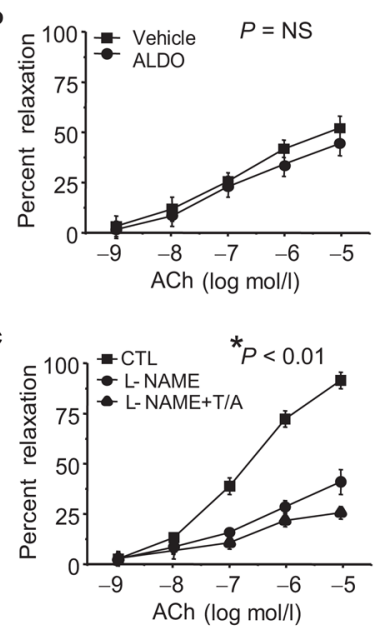
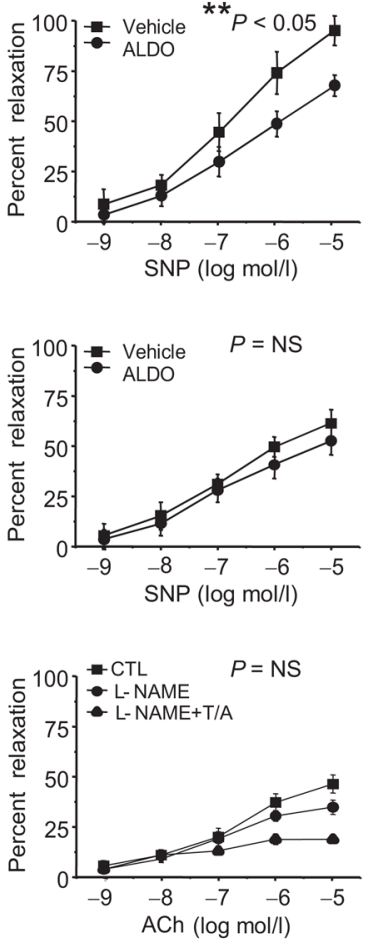

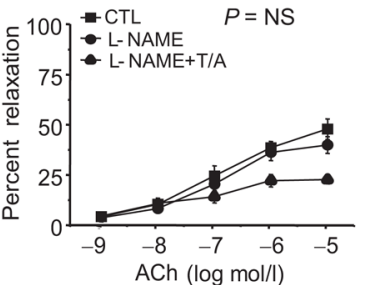

Figure 5. Aldosterone impairs vascular reactivity

Mice were infused with aldosterone (50 $\mu \mathrm{g} / \mathrm{kg} /$ day) (ALDO) or vehicle (V) via Alzet minipump for $14 \mathrm{~d}$ and vascular reactivity was measured using intravital videomicroscopy to visualize vasodilation of mesenteric arterioles in response to superfusion of vasodilators after preconstriction with phenylephrine $(10 \mu \mathrm{mol} / \mathrm{L})$. The vascular response to increasing concentrations of acetylcholine (ACh) and sodium nitroprusside (SNP) was examined in (a) ALDO-infused wild-type mice and compared to $\mathrm{V}$-infused wild-type mice $(* P<0.03$ by ANOVA; $* * P<0.05$ by ANOVA; $\mathrm{n}=12$ per treatment group); (b) ALDO-infused G6pddeficient male mice and compared to V-infused G6pd-deficient male mice ( $P=$ NS by ANOVA; $\mathrm{n}=8$ per treatment group). (c) To determine the relative contribution of eNos and endothelium-derived hyperpolarizing factor to vascular reactivity, mice were superfused with L-NAME $(1 \mathrm{mmol} / \mathrm{L})$ or L-NAME, TRAM-34 $(1 \mu \mathrm{mol} / \mathrm{L})$, and Apamin $(10 \mu \mathrm{mol} / \mathrm{L})$ (L-NAME+T/A) prior to ACh superfusion. Responses are shown for wild-type mice $(\mathrm{n}=5)$ $(* P<0.01$ by ANOVA) (left); ALDO-infused wild-type mice $(\mathrm{n}=5)(P=$ NS by ANOVA) (middle); and V-infused G6pd-deficient mice $(\mathrm{n}=5)(P=\mathrm{NS}$ by ANOVA) (right). Data represent mean $\pm \mathrm{SEM}$. 

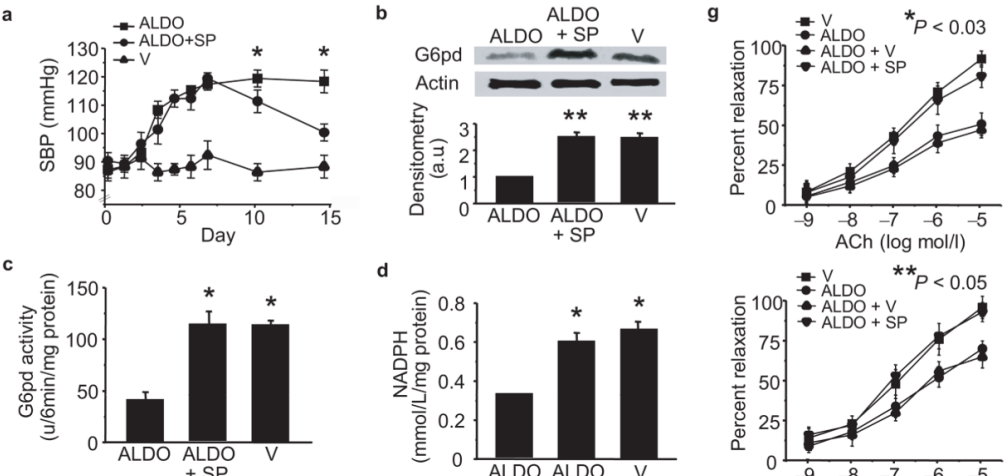

d
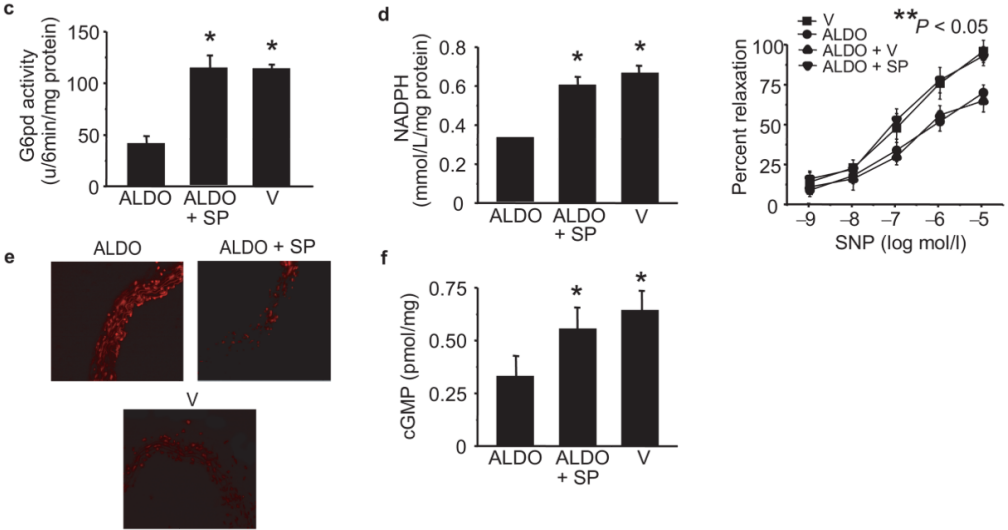

Figure 6. Spironolactone increases G6pd to improve vascular reactivity

$\mathrm{C} 3 \mathrm{H}$ wild-type mice were infused with aldosterone $(50 \mu \mathrm{g} / \mathrm{kg} / \mathrm{day})(\mathrm{ALDO})(\mathrm{n}=20)$ or vehicle $(\mathrm{V})(\mathrm{n}=20)$ via Alzet minipump for $14 \mathrm{~d}$ in the absence or presence of spironolactone $(20 \mathrm{mg} / \mathrm{kg} / \mathrm{d})(\mathrm{ALDO}+\mathrm{SP})(\mathrm{n}=20)$ added in the drinking water for the final $7 \mathrm{~d}$ of the $14 \mathrm{~d}$ treatment period, and (a) systolic blood pressure was measured by tail cuff $(* P<0.01$ vs. ALDO). After the $14 \mathrm{~d}$ treatment period, aortas were harvested and (b) G6pd expression, (c) activity, and (d) Nadph levels were measured in tissue homogenates ( $* P<$ 0.01 vs. ALDO, $\mathrm{n}=10$ ). (e) Reactive oxygen species were examined in aorta sections by dihydroethidine fluorescence (200X magnification), and (f) cGMP levels were measured as an indicator of bioactive $\mathrm{NO}^{*}(* P<0.01$ vs. ALDO, $\mathrm{n}=6)$. Vascular reactivity was assessed by intravital videomicroscopy to increasing concentrations of $(\mathrm{g})$ acetylcholine (Ach) $(* P<$ 0.03 by ANOVA, $\mathrm{n}=8)$ or sodium nitroprusside (SNP) $(* * P<0.05$ by ANOVA, $\mathrm{n}=8)$. Densitometry was performed on a minimum of three blots and reported as arbitrary units (a.u.). Data represent mean \pm SEM. 